\title{
Resenha do livro Sobre a arte de guardar: reflexões a respeito do acervo de Lívio Xavier
}

\author{
Jean Marcel Caum Camoleze \\ Doutorando; Universidade Estadual Paulista Júlio de Mesquita Filho, Marília, SP, Brasil; \\ jean.camoleze@unesp.br
}

TROITIÑO, S., LUCA, T. R. (org.). Sobre a arte de guardar: reflexões a respeito do acervo de Lívio Xavier. São Paulo: Cultura Acadêmica, 2017.

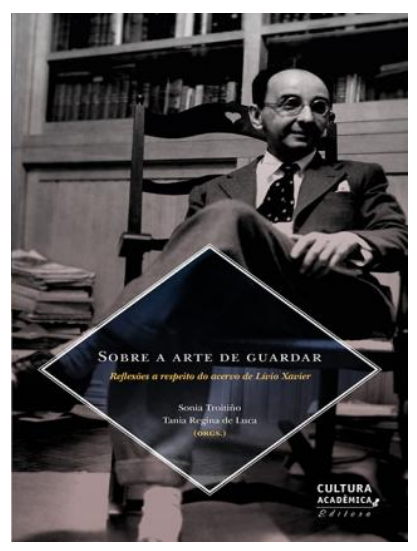

Resumo: Esta resenha tem por finalidade evidenciar as contribuições do livro Sobre a arte de guardar: reflexões a respeito do acervo de Lívio Xavier, que contém propostas para o preenchimento de duas lacunas; a primeira, um estudo sobre a trajetória pessoal, intelectual e profissional de Lívio Xavier; a segunda, pormenores sobre as potencialidades de um acervo pessoal de escritor. Além da apresentação inicial, escrita pelas organizadoras do livro, Sonia Troitiño e Tania Regina de Luca, a obra também é composta por dois grandes depoimentos de Antonio Candido e José Castilho Marques Neto e por seis capítulos que mesclam informações sobre as técnicas e práxis arquivistas, as instituições de guardas documentais e o acervo de Lívio Xavier. Durante todo o livro, são destacados os desafios sobre os estudos apresentados, porém, são igualmente abordados percursos técnicos e intelectuais para a organização de arquivos com grande diversidade documental e o fomento à pesquisa em diversos campos do saber.

Palavras-chave: Organização arquivística. Arquivo pessoal. Documentação histórica.

Lívio Barreto Xavier, nascido no dia 25 de abril do último ano do século XIX, na cidade de Granja, Ceará (CE), formado em direito e dedicado às causas trabalhistas, foi escritor, jornalista e tradutor de importantes obras, como Ética, de Baruch de Spinoza,de 1937, Reforma e revolução, de Rosa Luxemburgo, de 
1946, O Príncipe, de Nicolau Maquiavel, de 1940, e Minha Vida e Terrorismo e Comunismo, de Léon Trotsky, de 1969. Lívio Xavier também foi um importante militante da esquerda brasileira, com ingresso no Partido Comunista do Brasil (PCB), em 1927, tendo se desfiliado um ano depois. As divergências com a direção do PCB e as afinidades com Mario Pedrosa, que residia na Europa, aproximaram Lívio Xavier das ideias da Oposição Internacional de Esquerda. Liderada por León Trostky, a oposição era uma organização comunista e oposicionista das medidas ideológicas e políticas implantadas por Josef Stalin, na União Soviética, após a morte de Vladimir Lenin.

Estudioso de Napoleão Bonaparte, ao qual se referia como "o último grande destino da História" e da Revolução Russa, de que tinha conhecimento amplo e uma raríssima coleção de livros e panfletos, Xavier deixou a militância política em 1935 e passou a advogar na área trabalhista como procurador da Justiça do Trabalho, atuando principalmente nos Sindicatos dos Jornalistas, dos Ferroviários da Sorocabana e dos Gráficos, desde os anos de 1930 até sua aposentadoria. Também se dedicou aos escritos jornalísticos, especialmente no campo da crítica literária. Suas contribuições, como jornalista, foram publicadas nos jornais $O$ Estado de $S$. Paulo e Diário de S. Paulo e no suplemento Revista das Revistas, que foi idealizado e realizado pelo próprio escritor, onde foram divulgados aproximadamente quatrocentos artigos referentes a críticas literárias, musicais e outros assuntos.

Toda essa trajetória de Lívio Xavier na militância política, no exercício da advocacia e na sua produção literária, além de revelar um vasto conhecimento, proporcionou a constituição de um esplêndido acervo documental e bibliográfico. $\mathrm{O}$ acervo foi transferido ao Centro de Documentação e Memória (CEDEM) da Universidade Estadual Paulista "Júlio de Mesquita Filho" (UNESP), em 1994, quando ainda se encontrava sob responsabilidade do Centro de Documentação do Movimento Operário Mário Pedrosa(CEMAP). Posteriormente, foi adquirido pela UNESP, em 2002, por meio da mediação da professora Myriam Xavier Fragoso, sobrinha de Lívio. Com isso, a documentação e a biblioteca com diversas obras raras se tornaram 


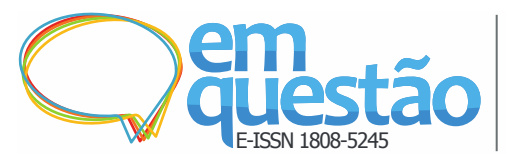

Resenha do livro Sobre a arte de guardar: reflexôes a respeito do acervo de Lívio Xavier

Jean Marcel Caum Camoleze

um patrimônio coletivo e ficaram disponíveis para a pesquisa e o fomento cultural.

Atualmente, esse conjunto de materiais está acondicionado e custodiado no CEDEM, que recebe o nome de Fundo Lívio Xavier (FLX) é:

[...] constituído de documentos referentes à sua militância política nas organizações trotskistas, tais como: relatórios, teses, resoluções de congressos de partidos comunistas e, ainda, sua correspondência com Mário Pedrosa, Benjamin Péret e Elsie Houston (CAMARGO, 2008, p. 78).

Além disso, ele é composto por documentos textuais acondicionados em quarenta e duas caixas de arquivos, documentos iconográficos - sendo trezentos e noventa retratos, duzentos e vinte e dois postais, quatro ampliações fotográficas e cinquenta e um negativos - e documentos bibliográficos divididos em noventa e cinco periódicos e quatro mil e trinta e oito livros.

No entanto, segundo as organizadoras do livro, mesmo com um acervo de grande dimensão documental e repleto de elementos importantes para a compreensão intelectual e política do Brasil, no século XX, o Fundo Lívio Xavier é pouco explorado e isso tem reduzido as potencialidades da produção historiográfica e de outros diversos temas como críticas literárias e política que Lívio Xavier transpassou em sua vida. Nesse intuito, o livro tem um papel fundamental, pois reúne especialistas capazes de difundir o valor do acervo em questão, além de debater e refletir sobre as técnicas de arquivologia de patrimônios pessoais e sobre a importância da recuperação da informação para a pesquisa científica e acadêmica.

Após a apresentação das organizadoras do livro, temos o primeiro depoimento, intitulado "Preâmbulo", que é assinado por José Castilho Marques Neto, diretor-presidente da Editora UNESP. Mesmo a obra sendo voltada para o acervo de Lívio Xavier, o autor faz uma equitativa e coerente homenagem a Antônio Candido. Marques Neto relembra, em seu texto, conversas com Antônio Candido sobre a importância de uma publicação que apresente a vida, o acervo e um justo reconhecimento a esse intelectual brasileiro. 
Em seguida, temos um inolvidável depoimento de Antonio Candido, talvez um dos seus últimos escritos, antes de seu falecimento, com o título de "Lívio Barreto Xavier - minha impressão pessoal”. Exaltando Lívio Xavier como "um homem de grande talento, cultura e originalidade", ele escreve seu texto como admirador e amigo. Por meio de uma analogia, o autor descreve as qualidades de Lívio Xavier como crítico, jornalista e cronista, sempre ressaltando sua intelectualidade e sua vocação para a reflexão sobre as manifestações artísticas e o cenário político nacional e internacional. As suas características de militante, como advogado ou como político também fazem parte do depoimento, sempre destacando que Xavier não demostrou inibição ou comodismo, mesmo com suas limitações físicas, em consequência de paralisação sofrida do seu lado direito.

As memórias e vivências de Antonio Candido, ao lado de Lívio Xavier, fazem parte igualmente desse momento do livro, como os encontros quase diários no Bar Hitler, na Rua Barão de Itapetininga, em São Paulo, ou em viagem realizada pelo Brasil, junto a Myriam Xavier Fragoso.

O escrito de Antonio Candido deixa evidente que, além de Lívio Xavier ter obtido grande destaque como escritor e jornalista, também era um profundo conhecedor de diversos assuntos históricos, como a Revolução Russa e Napoleão Bonaparte, com imensa capacidade para análise política e social. Assim, esse depoimento constitui uma excelente introdução para conhecer mais sobre o autor em questão e compreender por que ele era chamado de "mestre dos mestres".

Em seguida, José Castilho Marques Neto retoma seus escritos, no capítulo primeiro, com o título de "Na biblioteca de Lívio Xavier - Lembranças de um jovem pesquisador". Seguindo a mesma linha de Antonio Candido, Marques Neto descreve suas lembranças, conhecimentos e admiração sobre ele. $\mathrm{O}$ autor exalta a sua vida e a sua curta militância política no Partido Comunista do Brasil (PCB), a qual foi de grande importância para o trotskismo no contexto brasileiro, pois Xavier traduzia oficialmente os textos desse autor.

No segundo capítulo, iniciam-se os escritos acerca de trabalhos intelectuais e técnicos dentro dos arquivos, principalmente de arquivos pessoais 
e de militantes políticos. Elisabete Maria Ribas, supervisora técnica do Serviço de Arquivo do Instituto de Estudos Brasileiros da Universidade de São Paulo (IEB-USP), escreve a respeito do conjunto documental do qual faz parte o acervo de Lívio Xavier, os arquivos pessoais, especificamente arquivos pessoais de escritores. Segundo a autora, na definição de arquivos pessoais, temos embutido a própria acepção de arquivos privados, onde os documentos estão ligados às obras e às atividades de uma pessoa, diferenciando-se de documentos funcionais e administrativos, no sentido laboral.

A autora, no segundo capítulo, também apresenta algumas instituições nacionais que se dedicam à salvaguarda de arquivos pessoais, sobretudo de escritores: o Instituto de Estudos Brasileiros, o Arquivo Museu de Literatura Brasileira, o Centro de Documentação Cultural Alexandre Eulalio, o Instituto Moreira Salles, o Arquivo dos Escritores Mineiros, o Espaço de Documentação e Memória e o Centro de Documentação e Apoio à Pesquisa.

Ressaltando a abrangência, complexidade e multiplicidade de uma vida arquivada, Ribas mostra como os arquivos pessoais de escritores carregam consigo uma grande diversidade de produção documental, especialmente pelas várias funções e atividades que esses escritores exercem, ao longo de suas trajetórias. Esses elementos, muitas vezes, criam um grande desafio para a organização arquivística, principalmente pela não existência de uma forma unívoca da obra do escritor. Porém, a autora destaca que, mesmo com as dificuldades da organização, os arquivos pessoais precisam ser guardados, identificados e classificados, a fim de serem abertos para o desenvolvimento de novas pesquisas. Ao final do capítulo, a autora conclui que essas ações, para fomentar e difundir a pesquisa, a partir de acervos pessoais de escritores, ocorrem com o Fundo Lívio Xavier, por estar em um lócus privilegiado da guarda documental.

No capítulo seguinte, uma das organizadoras do livro, Sonia Troitiño, aborda a formação do arquivo de Lívio Xavier. A coordenadora do CEDEM/UNESP, local de guarda do Fundo Lívio Xavier, salienta o hábito do escritor em reunir informações e, utilizando o termo de Philippe Lejeune, define o escritor como um "guardador de memórias". No entanto, esse capítulo tem 
destaque, ao promover a relevância da contextualização dos acervos, dentro de uma conjunção de produção e guarda. Com isso, podemos entender que a grande disparidade de documentos produzidos durante a carreira do escritor e a imensa quantidade de tipos documentais encontrados no acervo têm um propósito e uma motivação estimulada pela trajetória e pelas ideias do próprio autor.

Dessa forma, a autora do terceiro capítulo enfatiza os desafios da organização de arquivos pessoais, partindo do Fundo Lívio Xavier, o qual serve de parâmetro de arranjo, de organização e de descrição a arquivos pessoais de escritores e militantes políticos, oferecendo subsídios para pesquisas referentes a produção documental semelhante. A autora sublinha a importância da compreensão do desígnio bibliográfico do autor e de sua vida social, para estabelecer os critérios de organização e guarda do acervo. Logo, como uma consequência da análise da produção documental inserida no contexto do próprio autor do arquivo, temos a inerência da concepção tradicional do princípio da naturalidade da produção documental de arquivos. Dessa maneira, a lógica da contextualização segue o princípio da proveniência, compreendendo a origem comum dos documentos produzidos e seus lugares na composição do arquivo, reconhecendo-se a titularidade e o contexto da formação do acervo.

Neste ponto, retomamos a mesma motivação exposta no capítulo anterior: o acesso e a recuperação da informação, nos arquivos pessoais de escritores, a qual muitas vezes está oculta ou de difícil acesso, por causa da falta de organização ou da ausência de elementos de difusão. Por isso, é fundamental o serviço de organização e utilização de metodologias adequadas, aliadas à fundamentação teórica e da práxis, de modo a colocar as informações em condição de apreensão e de uso pleno.

No capítulo quarto, a correspondência dentro do acervo de Lívio Xavier é o tema central discutido pela outra organizadora do livro, Tania Regina de Luca. As correspondências são uma comunicação escrita expedida ou recebida, que, nos arquivos pessoais aparecem sobretudo sob o tipo de cartas. A autora destaca que as cartas são fontes históricas, que despertam grande interesse aos pesquisadores e trazem consigo diversos elementos, intrínsecos e extrínsecos, 
capazes de auxiliar na compreensão do mundo no qual foram produzidas e estão inseridas.

Após realizar uma expansão histórica sobre a produção das cartas e sua composição e logística, a autora volta-se para as cartas inseridas no acervo de Lívio Xavier, apresentando a pluralidade de correspondências que foram recebidas pelo escritor, as quais variam de cartas recebidas do interior do Ceará, de um amigo de infância, da escrita por Caio Prado Júnior, que explicava a discordância em relação à leitura de Evolução Política do Brasil e tantas outras que envolviam relevantes debates com diversos intelectuais brasileiros e estrangeiros.

Com isso, a autora demonstra que, além das correspondências servirem como referência para compreender o percurso biográfico e a formação e difusão das ideias de Lívio Xavier, as cartas em acervos pessoais contribuem ainda para entender os campos políticos, literários, artísticos e sociais, no contexto no qual o autor estava inserido.

“O legado do Modernismo na crítica de Lívio Xavier” é o título do quinto capítulo do livro, escrito por Sílvia Maria Azevedo, Livre-Docente em Teoria Literária pela UNESP. Lívio Xavier produziu vastas críticas ao Movimento Modernista, principalmente a Mário e Oswald de Andrade. Segundo a autora, o lado de crítico literário do autor é pouco pesquisado e precisa ser mais divulgado. No ano de 1975, sessenta e oito textos de Lívio Xavier com críticas literárias publicadas em jornais foram reunidos em um livro, cujo nome era $O$ elmo de Mambrino, que lhe rendeu o Prêmio Jabuti, na categoria Estudos Literários (Ensaios). O livro tem, em seu primeiro capítulo, uma crítica a Oswald de Andrade, principalmente a sua obra dramatúrgica, onde Lívio Xavier chama os escritos do modernista de revolucionarismo primário, fazendo referência à guinada à esquerda do fundador do Movimento Antropofágico.

A autora também ressalta, nesse capítulo, as críticas de Lívio Xavier ao Movimento Antropofágico, ao exaltar que o movimento não passava de um dos muitos mitos surgidos da imaginação de Oswald de Andrade, na sua incessante atividade literária. Com isso, percebe-se que, mesmo as críticas de Lívio Xavier estando concentradas nas contribuições de Mário de Andrade e Oswald de 
Andrade, constituem uma grande contribuição aos estudos sobre o Movimento Modernista, por meio de um posicionamento estético-ideológico coerente.

No capítulo que encerra o livro, discute-se a fotografia como um gênero iconográfico frequentemente encontrado em arquivos pessoais. Telma Campanha de Carvalho Madio, Livre-Docente em Documento Fotográfico, traz nesse capítulo importantes contribuições não apenas no âmbito do acervo de Lívio Xavier, mas sobretudo do local da fotografia dentro do arquivo.

Segundo a autora, para a organização do documento fotográfico, temos que considerar sua produção e/ou a guarda original. Assim, após explanar sobre a fotografia, suas técnicas e sua importância no mundo contemporâneo, a autora destaca a fotografia como um documento que contém indícios do passado e é fonte imprescindível para os estudos e pesquisas históricas e sociológicas. Com isso, o registro fotográfico passou a ser "quase" obrigatório, ampliando de maneira significativa sua quantidade em acervos documentais, principalmente em arquivos pessoais, onde são gravadas atividades profissionais, familiares ou de amizades vinculadas à trajetória do titular do acervo.

Desse modo, a fotografia precisa ter seu lugar definido dentro do arquivo e não ser tratada como um documento isolado. A autora enfatiza a importância de conhecer a trajetória do titular, identificando a função da fotografia e contextualizando-a, juntamente com os demais documentos do acervo.

Nesse estudo, a autora identifica os desafios de trabalhar a organização fotográfica nos arquivos, seja pela falta de identificação, seja, muitas vezes, em função de uma separação por suporte, que dificulta a contextualização da fotografia, no acervo. No entanto, isso não anula a necessidade de compreender a guarda da fotografia pelo titular em determinado local, no acervo, e nem a de entender a função e a contextualização da imagem.

A autora encerra o capítulo e o livro, mostrando a relevância do entendimento da formação do arquivo e da trajetória do titular para a organização das fotografias e dos demais documentos, dentro do acervo. Mesmo apontando as dificuldades e os desafios da organização da fotografia, nos 
acervos, a autora traça um caminho a percorrer, para pôr em prática a melhor forma de recuperar as informações contidas nas fotografias arquivadas.

Dessa forma, ao terminar o livro, podemos perceber que foram escritas excelentes contribuições sobre os estudos de Lívio Xavier e referentes às técnicas de guarda de arquivos pessoais de escritores.

\title{
Referências
}

CAMARGO, C. R. (org.). Guia do acervo - CEDEM. São Paulo: CEDEM, 2008.

TROITIÑO, S., LUCA, T. R. (org.). Sobre a arte de guardar: reflexões a respeito do acervo de Lívio Xavier. São Paulo: Cultura Acadêmica, 2017.

\section{Book review Sobre a arte de guardar: reflexões a respeito do acervo de Lívio Xavier}

\begin{abstract}
This review aims to highlight the contributions of the book Sobre a arte de guardar: reflexões a respeito do acervo de Lívio Xavier (About the art of saving: reflections on the collection of Lívio Xavier), which contains proposals for filling two gaps; the first, a study on the personal, intellectual and professional trajectory of Livio Xavier; the second, details about the potentialities of a writer's personal collection. Besides the initial presentation, written by the organizers of the book, Sonia Troitiño and Tania Regina de Luca, the work is also composed of two great testimonies of Antonio Candido and José Castilho Marques Neto and six chapters that mix information on archival techniques and praxis, the institutions of documentary guards and the collection of Lívio Xavier. Throughout the book, the challenges of the studies presented are highlighted. However, technical and intellectual paths are also addressed for the organization of archives with a great diversity of documents and the research promotion in several fields of knowledge.
\end{abstract}

Keywords: Archival organization. Personal archive. Historical documentation.

Recebido: $15 / 10 / 2018$

Aceito: 20/02/2019 